\title{
Bases in finite groups of small order
}

\begin{abstract}
Banakh T.O. ${ }^{1,2}$, Gavrylkiv V.M. ${ }^{3}$
A subset $B$ of a group $G$ is called a basis of $G$ if each element $g \in G$ can be written as $g=a b$ for some elements $a, b \in B$. The smallest cardinality $|B|$ of a basis $B \subseteq G$ is called the basis size of $G$ and is denoted by $r[G]$. We prove that each finite group $G$ has $r[G]>\sqrt{|G|}$. If $G$ is Abelian, then $r[G] \geq \sqrt{2|G|-|G| /\left|G_{2}\right|}$, where $G_{2}=\left\{g \in G: g^{-1}=g\right\}$. Also we calculate the basis sizes of all Abelian groups of order $\leq 60$ and all non-Abelian groups of order $\leq 40$.

Key words and phrases: finite group, Abelian group, basis, basis size, basis characteristic.
\end{abstract}

\footnotetext{
${ }^{1}$ Ivan Franko Lviv National University, 1 Universytetska str., 79000, Lviv, Ukraine

2 Institute of Mathematics, Jan Kochanowski University in Kielce, 7 Uniwersytecka str., 25406, Kielce, Poland

${ }^{3}$ Vasyl Stefanyk Precarpathian National University, 57 Shevchenka str., 76018, Ivano-Frankivsk, Ukraine

E-mail: t.o.banakh@gmail.com (Banakh T.O.), vgavrylkiv@gmail.com (Gavrylkiv V.M.)
}

\section{Introduction}

A subset $B$ of a group $G$ is called a basis of $G$ if each element $g \in G$ can be written as $g=a b$ for some $a, b \in B$. The smallest cardinality of a basis of $G$ is called the basis size of $G$ and is denoted by $r[G]$. The problem of estimating $r[G]$ for cyclic groups was first proposed by I. Schur and various bounds were obtained by H. Rohrbach [16], L. Moser [12], A. Stöhr [18], W. Klotz [10] and others. Bases for arbitrary groups were investigated by H. Rohrbach [17] and lately by J. Cherly [7], E.A. Bertram, M. Herzog [6], M.B. Nathanson [14], G. Kozma and A. Lev [19].

The definition of a basis $B$ for a group $G$ implies that $|G| \leq|B|^{2}$ and hence $r[G] \geq \sqrt{|G|}$. The fraction

$$
\delta[G]:=\frac{r[G]}{\sqrt{|G|}} \geq 1
$$

is called the basis characteristic of $G$.

For a class $\mathcal{G}$ of finite groups the number

$$
\delta[\mathcal{G}]=\sup _{G \in \mathcal{G}} \delta[G]
$$

is called the basis characteristic of the class $\mathcal{G}$. By Groups we shall denote the class of all finite groups.

In this paper we are interested in evaluating the basis characteristics of finite groups. In fact, this problem has been studied in the literature. In particular, G. Kozma and A. Lev [19] proved that each finite group $G$ has basis characteristic $\delta[G] \leq \frac{4}{\sqrt{3}} \approx 2.3094$. 
A standard model of a cyclic group of order $n$ is the multiplicative group

$$
C_{n}=\left\{z \in \mathbb{C}: z^{n}=1\right\}
$$

of $n$-th roots of 1 . The group $C_{n}$ is isomorphic to the additive group of the ring $\mathbb{Z}_{n}=\mathbb{Z} / n \mathbb{Z}$.

For a real number $x$ we put

$$
\lceil x\rceil=\min \{n \in \mathbb{Z}: n \geq x\} \text { and }\lfloor x\rfloor=\max \{n \in \mathbb{Z}: n \leq x\} .
$$

\section{Known results}

In this section we recall some known results on bases in finite groups. The following fundamental fact was proved by G. Kozma and A. Lev [19] (using the classification of finite simple groups).

Theorem 1 ([19]). Each finite group $G$ has the basis characteristic $\delta[G] \leq \frac{4}{\sqrt{3}}$.

The following proposition was proved by E.A. Bertram and M. Herzog.

Proposition 1 ([6]). Let $G$ be a finite group. Then

1) $r[G] \leq|G: H| \cdot r[H]$ for any subgroup $H \subseteq G$;

2) $r[G] \leq r[G / H] \cdot|H|$ for any normal subgroup $H \subseteq G$;

3) $r[G] \leq 2 r[G / H] \cdot r[H]$ for any normal subgroup $H \subseteq G$;

4) $r[G] \leq r[G / H] \cdot r[H]$ for any subgroup $H \subseteq Z(G)$;

5) $r[G] \leq|H|+|G: H|-1$ for any subgroup $H \subseteq G$.

In Proposition 1 by $Z(G)=\{z \in G: \forall x \in G(x z=z x)\}$ the center of $G$ is denoted.

The following theorem on lower bounds of basis size of Abelian groups was proved by E.A. Bertram and M. Herzog.

Theorem 2 ([6]). Each finite Abelian group $G$ has the basis size

$$
r[G] \geq \frac{1}{2}(\sqrt{8|G|+1}-1) .
$$

The following upper bound on the basis size of cyclic groups was obtained by E.A. Bertram and M. Herzog in [6].

Theorem 3 ([6]). For any $n>2$ the cyclic group $C_{n}$ has the basis size

$$
r\left[C_{n}\right]<2 \sqrt{n-1}
$$


The upper bound in Theorem 3 can be asymptotically improved using the old result of A. Mrose.

Theorem 4 ([13]). For a sufficiently large $n$, the cyclic group $C_{n}$ has basis size

$$
r\left[C_{n}\right] \leq \sqrt{\frac{7}{2} n} \approx 1.87 \sqrt{n}
$$

The constant $\sqrt{\frac{7}{2}} \approx 1.87$ was recently improved by J. Kohonen in [11].

Theorem 5 ([11]). For a sufficiently large $n$, the cyclic group $C_{n}$ has basis size

$$
r\left[C_{n}\right] \leq \sqrt{\frac{294}{85} n} \approx 1.86 \sqrt{n}
$$

Bases in dihedral and Boolean groups were investigated in [8].

In evaluating the basis characteristics of groups we can use their difference characteristics. A subset $B$ of a group $G$ is called a difference basis of $G$ if each element $g \in G$ can be written as $g=x y^{-1}$ for some $x, y \in B$. The smallest cardinality of a difference basis of $G$ is called the difference size of $G$ and is denoted by $\Delta[G]$. The definition of a difference basis $B$ for a group $G$ implies that $|G| \leq|B|^{2}$ and hence $\Delta[G] \geq \sqrt{|G|}$. The fraction

$$
\partial[G]:=\frac{\Delta[G]}{\sqrt{|G|}} \geq 1
$$

is called the difference characteristic of $G$.

Difference bases and difference characteristics in dihedral and Abelian groups were investigated in [3,4]. Difference bases have applications in the study of structure of superextensions of groups, see $[1,5,9]$.

The following facts on the difference characteristics of cyclic groups were proved in [2].

Theorem 6 ([2]). For any $n \in \mathbb{N}$ the cyclic group $C_{n}$ has the difference characteristic:

1) $\precsim\left[C_{n}\right] \leq ð\left[C_{4}\right]=\frac{3}{2}$

2) $\partial\left[C_{n}\right] \leq ð\left[C_{2}\right]=ð\left[C_{8}\right]=\sqrt{2}$ if $n \neq 4$;

3) $\mathrm{\partial}\left[C_{n}\right] \leq \frac{12}{\sqrt{73}}<\sqrt{2}$ if $n \geq 9$;

4) $\partial\left[C_{n}\right] \leq \frac{24}{\sqrt{293}}<\frac{12}{\sqrt{73}}$ if $n \geq 9$ and $n \neq 292$;

5) $\partial\left[C_{n}\right]<\frac{2}{\sqrt{3}}$ if $n \geq 2 \cdot 10^{15}$.

The following Table 1 of difference sizes and characteristics of cyclic groups $C_{n}$ for $\leq 100$ is taken from [2]. 


\begin{tabular}{|c|c|c||c|c|c||c|c|c||c|c|c|}
\hline$n$ & $\Delta\left[C_{n}\right]$ & $\partial\left[C_{n}\right]$ & $n$ & $\Delta\left[C_{n}\right]$ & $\partial\left[C_{n}\right]$ & $n$ & $\Delta\left[C_{n}\right]$ & $\partial\left[C_{n}\right]$ & $n$ & $\Delta\left[C_{n}\right]$ & $\partial\left[C_{n}\right]$ \\
\hline 1 & 1 & 1 & 26 & 6 & $1.1766 \ldots$ & 51 & 8 & $1.1202 \ldots$ & 76 & 10 & $1.1470 \ldots$ \\
2 & 2 & $1.4142 \ldots$ & 27 & 6 & $1.1547 \ldots$ & 52 & 9 & $1.2480 \ldots$ & 77 & 10 & $1.1396 \ldots$ \\
3 & 2 & $1.1547 \ldots$ & 28 & 6 & $1.1338 \ldots$ & 53 & 9 & $1.2362 \ldots$ & 78 & 10 & $1.1322 \ldots$ \\
4 & 3 & 1.5 & 29 & 7 & $1.2998 \ldots$ & 54 & 9 & $1.2247 \ldots$ & 79 & 10 & $1.1250 \ldots$ \\
5 & 3 & $1.3416 \ldots$ & 30 & 7 & $1.2780 \ldots$ & 55 & 9 & $1.2135 \ldots$ & 80 & 11 & $1.2298 \ldots$ \\
6 & 3 & $1.2247 \ldots$ & 31 & 6 & $1.0776 \ldots$ & 56 & 9 & $1.2026 \ldots$ & 81 & 11 & $1.2222 \ldots$ \\
7 & 3 & $1.1338 \ldots$ & 32 & 7 & $1.2374 \ldots$ & 57 & 8 & $1.0596 \ldots$ & 82 & 11 & $1.2147 \ldots$ \\
8 & 4 & $1.4142 \ldots$ & 33 & 7 & $1.2185 \ldots$ & 58 & 9 & $1.1817 \ldots$ & 83 & 11 & $1.2074 \ldots$ \\
9 & 4 & $1.3333 \ldots$ & 34 & 7 & $1.2004 \ldots$ & 59 & 9 & $1.1717 \ldots$ & 84 & 11 & $1.2001 \ldots$ \\
10 & 4 & $1.2649 \ldots$ & 35 & 7 & $1.1832 \ldots$ & 60 & 9 & $1.1618 \ldots$ & 85 & 11 & $1.1931 \ldots$ \\
11 & 4 & $1.2060 \ldots$ & 36 & 7 & $1.1666 \ldots$ & 61 & 9 & $1.1523 \ldots$ & 86 & 11 & $1.1861 \ldots$ \\
12 & 4 & $1.1547 \ldots$ & 37 & 7 & $1.1507 \ldots$ & 62 & 9 & $1.1430 \ldots$ & 87 & 11 & $1.1793 \ldots$ \\
13 & 4 & $1.1094 \ldots$ & 38 & 8 & $1.2977 \ldots$ & 63 & 9 & $1.1338 \ldots$ & 88 & 11 & $1.1726 \ldots$ \\
14 & 5 & $1.3363 \ldots$ & 39 & 7 & $1.1208 \ldots$ & 64 & 9 & 1.125 & 89 & 11 & $1.1659 \ldots$ \\
15 & 5 & $1.2909 \ldots$ & 40 & 8 & $1.2649 \ldots$ & 65 & 9 & $1.1163 \ldots$ & 90 & 11 & $1.1595 \ldots$ \\
16 & 5 & 1.25 & 41 & 8 & $1.2493 \ldots$ & 66 & 10 & $1.2309 \ldots$ & 91 & 10 & $1.0482 \ldots$ \\
17 & 5 & $1.2126 \ldots$ & 42 & 8 & $1.2344 \ldots$ & 67 & 10 & $1.2216 \ldots$ & 92 & 11 & $1.1468 \ldots$ \\
18 & 5 & $1.1785 \ldots$ & 43 & 8 & $1.2199 \ldots$ & 68 & 10 & $1.2126 \ldots$ & 93 & 12 & $1.2443 \ldots$ \\
19 & 5 & $1.1470 \ldots$ & 44 & 8 & $1.2060 \ldots$ & 69 & 10 & $1.2038 \ldots$ & 94 & 12 & $1.2377 \ldots$ \\
20 & 6 & $1.3416 \ldots$ & 45 & 8 & $1.1925 \ldots$ & 70 & 10 & $1.1952 \ldots$ & 95 & 12 & $1.2311 \ldots$ \\
21 & 5 & $1.0910 \ldots$ & 46 & 8 & $1.1795 \ldots$ & 71 & 10 & $1.1867 \ldots$ & 96 & 12 & $1.2247 \ldots$ \\
22 & 6 & $1.2792 \ldots$ & 47 & 8 & $1.1669 \ldots$ & 72 & 10 & $1.1785 \ldots$ & 97 & 12 & $1.2184 \ldots$ \\
23 & 6 & $1.2510 \ldots$ & 48 & 8 & $1.1547 \ldots$ & 73 & 9 & $1.0533 \ldots$ & 98 & 12 & $1.2121 \ldots$ \\
24 & 6 & $1.2247 \ldots$ & 49 & 8 & $1.1428 \ldots$ & 74 & 10 & $1.1624 \ldots$ & 99 & 12 & $1.2060 \ldots$ \\
25 & 6 & 1.2 & 50 & 8 & $1.1313 \ldots$ & 75 & 10 & $1.1547 \ldots$ & 100 & 12 & 1.2 \\
\hline
\end{tabular}

Table 1: Difference sizes and characteristics of cyclic groups $C_{n}$ for $n \leq 100$.

\section{Basis sizes and characteristics of finite groups}

Theorem 7. For any non-trivial finite group $G$ we have $r[G] \leq 2 \cdot \Delta[G]-1$. If $G$ has even order, then $r[G] \leq 2 \cdot \Delta[G]-2$.

Proof. Choose any difference basis $D \subseteq G$ of cardinality $|D|=\Delta[G]$. Then $G=D D^{-1}$. Replacing $D$ by $x^{-1} D$ for any element $x \in D$, we can assume that $D$ contains the identity element $e$ of the group $G$.

The set $A=D \cup D^{-1}$ has cardinality $|A| \leq 2|D|-1$ and has $A A \supseteq D D^{-1}=G$, which means that $A$ is a basis and $r[G] \leq|A| \leq 2|D|-1=2 \cdot \Delta[G]-1$.

Now assume that $G$ has even order. Then $G$ contains an element $a$ or order 2, according to the Sylow Theorem $[15,1.6 .16]$. Since $D D^{-1}=G$, there are elements $b, c \in D$ with $a=b c^{-1}$. Then $c b^{-1}=a^{-1}=a=b c^{-1}$ and for the set $B=D b^{-1} \cup b D^{-1}$ we have

$$
\{e, a\} \subseteq D b^{-1} \cap b D^{-1}
$$

and hence $|B| \leq 2 \cdot|D|-2$. On the other hand,

$$
B B \supseteq\left(D b^{-1}\right) \cdot\left(b D^{-1}\right)=D D^{-1}=G
$$


and hence

$$
r[G] \leq|B| \leq 2 \cdot|D|-2=2 \cdot \Delta[G]-2 \text {. }
$$

In Table 2 we present the results of computer calculations of basis sizes and characteristics of cyclic groups of order $\leq 60$. In this table

$$
l b\left[C_{n}\right]:=\lceil\sqrt{2 n+0.25}-0.5\rceil
$$

is the lower bound given in Theorem 2 .

\begin{tabular}{|c|c|c|c||c|c|c|c||c|c|c|c|}
\hline$n$ & $l b\left[C_{n}\right]$ & $r\left[C_{n}\right]$ & $\delta\left[C_{n}\right]$ & $n$ & $l b\left[C_{n}\right]$ & $r\left[C_{n}\right]$ & $\delta\left[C_{n}\right]$ & $n$ & $l b\left[C_{n}\right]$ & $r\left[C_{n}\right]$ & $\delta\left[C_{n}\right]$ \\
\hline 1 & 1 & 1 & 1 & 21 & 6 & 7 & $1.5275 \ldots$ & 41 & 9 & 10 & $1.5617 \ldots$ \\
2 & 2 & 2 & $1.4142 \ldots$ & 22 & 7 & 8 & $1.7056 \ldots$ & 42 & 9 & 10 & $1.5430 \ldots$ \\
3 & 2 & 2 & $1.1547 \ldots$ & 23 & 7 & 8 & $1.6681 \ldots$ & 43 & 9 & 10 & $1.5249 \ldots$ \\
4 & 3 & 3 & 1.5 & 24 & 7 & 8 & $1.6329 \ldots$ & 44 & 9 & 11 & $1.6583 \ldots$ \\
5 & 3 & 3 & $1.3416 \ldots$ & 25 & 7 & 8 & 1.6 & 45 & 9 & 11 & $1.6397 \ldots$ \\
6 & 3 & 4 & $1.6329 \ldots$ & 26 & 7 & 8 & $1.5689 \ldots$ & 46 & 10 & 11 & $1.6218 \ldots$ \\
7 & 4 & 4 & $1.5118 \ldots$ & 27 & 7 & 8 & $1.5396 \ldots$ & 47 & 10 & 11 & $1.6045 \ldots$ \\
8 & 4 & 4 & $1.4142 \ldots$ & 28 & 7 & 9 & $1.7008 \ldots$ & 48 & 10 & 11 & $1.5877 \ldots$ \\
9 & 4 & 4 & $1.3333 \ldots$ & 29 & 8 & 8 & $1.4855 \ldots$ & 49 & 10 & 11 & $1.5714 \ldots$ \\
10 & 4 & 5 & $1.5811 \ldots$ & 30 & 8 & 8 & $1.4605 \ldots$ & 50 & 10 & 12 & $1.6970 \ldots$ \\
11 & 5 & 5 & $1.5075 \ldots$ & 31 & 8 & 9 & $1.6164 \ldots$ & 51 & 10 & 11 & $1.5403 \ldots$ \\
12 & 5 & 5 & $1.4433 \ldots$ & 32 & 8 & 9 & $1.5909 \ldots$ & 52 & 10 & 12 & $1.6641 \ldots$ \\
13 & 5 & 5 & $1.3867 \ldots$ & 33 & 8 & 9 & $1.5666 \ldots$ & 53 & 10 & 12 & $1.6483 \ldots$ \\
14 & 5 & 6 & $1.6035 \ldots$ & 34 & 8 & 9 & $1.5434 \ldots$ & 54 & 10 & 12 & $1.6329 \ldots$ \\
15 & 5 & 6 & $1.5491 \ldots$ & 35 & 8 & 9 & $1.5212 \ldots$ & 55 & 10 & 12 & $1.6180 \ldots$ \\
16 & 6 & 6 & 1.5 & 36 & 8 & 10 & $1.6666 \ldots$ & 56 & 11 & 12 & $1.6035 \ldots$ \\
17 & 6 & 6 & $1.4552 \ldots$ & 37 & 9 & 10 & $1.6439 \ldots$ & 57 & 11 & 12 & $1.5894 \ldots$ \\
18 & 6 & 7 & $1.6499 \ldots$ & 38 & 9 & 10 & $1.6222 \ldots$ & 58 & 11 & 13 & $1.7069 \ldots$ \\
19 & 6 & 6 & $1.3764 \ldots$ & 39 & 9 & 10 & $1.6012 \ldots$ & 59 & 11 & 12 & $1.5622 \ldots$ \\
20 & 6 & 7 & $1.5652 \ldots$ & 40 & 9 & 10 & $1.5811 \ldots$ & 60 & 11 & 13 & $1.6782 \ldots$ \\
\hline
\end{tabular}

Table 2: Basis sizes and characteristics of cyclic groups $C_{n}$ for $n \leq 60$.

The results of computer calculations suggest the following question.

Question 1. Is $\left|r\left[C_{n+1}\right]-r\left[C_{n}\right]\right| \leq 1$ for every $n \in \mathbb{N}$ ?

The results of computer calculations given in Table 2 imply the following lower and upper bounds for the basis characteristic of the class Cyclic of finite cyclic groups.

Proposition 2. The class Cyclic of finite cyclic groups has the basis characteristic

$$
1.7069 \cdots=\frac{13}{\sqrt{58}}=\delta\left[C_{58}\right] \leq \delta[\text { Cyclic }]<2 .
$$

Proof. The estimate for an upper bound of the basis characteristic for the class Cyclic of finite cyclic groups is $\delta$ [Cyclic] $<2$, see Theorem 3 . 
On the other hand, the basis size $r\left[C_{58}\right]=13$ of the cyclic group $C_{58}$ witnesses that

$$
1.7069 \cdots=\delta\left[C_{58}\right] \leq \delta[\text { Cyclic }] \text {. }
$$

Question 2. Is $\delta[$ Cyclic $]=\delta\left[C_{58}\right]=1.7069 \ldots$ ?

Next we establish some new lower bounds for the basis size of a finite (Abelian) group.

Theorem 8. Every finite Abelian group G has

$$
r[G] \geq \sqrt{2|G|-|G| /\left|G_{2}\right|} \text { and } \delta[G] \geq \sqrt{2-1 /\left|G_{2}\right|},
$$

where $G_{2}=\left\{g \in G: g^{-1}=g\right\}$.

Proof. Fix a basis $A \subseteq G$ of cardinality $|A|=r[G]$. Observe that $G_{2}$ coincides with the kernel of the homomorphism $h: G \rightarrow G, h: x \mapsto x^{2}$, and hence the image $h[G]$ has cardinality $\left|G / G_{2}\right|=|G| /\left|G_{2}\right|$. For every $y \in G \backslash h[G]$ there are elements $a, b \in A$ with $y=a b=b a$. It follows from $y \notin h[G]$ that $a \neq b$ and hence

$r[G]^{2}=|A \times A| \geq 2 \cdot|G \backslash h[G]|+|h[G]|=2 \cdot\left(|G|-|G| /\left|G_{2}\right|\right)+|G| /\left|G_{2}\right|=2 \cdot|G|-|G| /\left|G_{2}\right|$.

The proof of the following theorem was suggested by the Mathoverflow users lambda, user 49822 and Geoff Robinson, who answered a question posed by the first author at https://mathoverflow.net/q/384292/61536.

Theorem 9. Every non-trivial finite group $G$ has $r[G]>\sqrt{|G|}$.

Proof. To derive a contradiction, assume that $r[G]=\sqrt{|G|}$ for some finite group $G$. Choose a basis $B \subseteq G$ of cardinality $|B|=\sqrt{|G|}$. It follows that the multiplication map $\mu: B \times B \rightarrow G$, $\mu:(x, y) \mapsto x y$, is bijective. Consider the complex linear space $\mathbb{C}^{G}$ of functions from $G$ to the complex plane. Assign to each $g \in G$ the characteristic function of the singleton $\{g\}$. This is a unique function $\chi_{g}: G \rightarrow\{0,1\}$ such that $\chi_{g}^{-1}(1)=\{g\}$. It is clear that $\left\{\chi_{g}: g \in G\right\}$ is a basis of the linear space $\mathbb{C}^{G}$.

For every element $x \in G$, let $T_{x}: \mathbb{C}^{G} \rightarrow \mathbb{C}^{G}$ be the unique linear operator such that $T_{x}\left(\chi_{g}\right)=\chi_{x g}$ for every $g \in G$. It is easy to see that $T_{x} \circ T_{y}=T_{x y}$ for any elements $x, y \in G$. The operators $T_{g}, g \in G$, are elements of the algebra $\operatorname{End}\left(\mathbb{C}^{G}\right)$ of linear endomorphisms of the linear space $\mathbb{C}^{G}$.

Consider the endomorphisms

$$
\Phi=\frac{1}{|B|} \sum_{b \in B} T_{b} \quad \text { and } \quad E=\frac{1}{|G|} \sum_{g \in G} T_{g} .
$$

Observe that for any $g \in G$ we have

$$
E \circ T_{g}=\frac{1}{|G|} \sum_{x \in G} T_{x} \circ T_{g}=\frac{1}{|G|} \sum_{x \in G} T_{x g}=\frac{1}{|G|} \sum_{y \in G} T_{y}=E
$$


and

$$
T_{g} \circ E=\frac{1}{|G|} \sum_{x \in G} T_{g} \circ T_{x}=\frac{1}{|G|} \sum_{x \in G} T_{g x}=\frac{1}{|G|} \sum_{y \in G} T_{y}=E .
$$

Also

$$
E \circ E=\frac{1}{|G|} \sum_{x \in G} T_{x} \circ E=\frac{1}{|G|} \sum_{x \in G} E=E .
$$

The bijectivity of the multiplication map $\mu: B \times B \rightarrow G$ implies

$$
\Phi \circ \Phi=\frac{1}{|B|^{2}} \sum_{a, b \in B} T_{a} \circ T_{b}=\frac{1}{|G|} \sum_{a, b \in B} T_{a b}=\frac{1}{|G|} \sum_{g \in G} T_{g}=E .
$$

It follows that

$$
(\Phi-E) \circ(\Phi-E)=\Phi \circ \Phi-E \circ \Phi-\Phi \circ E+E \circ E=E-E-E+E=0
$$

which means that the endomorphism $\Phi-E$ is nilpotent and hence has trace equal to zero. The bijectivity of the multiplication map $\mu$ implies that the basis $B$ does not contain the identity $e$ of the group $G$. Then for every $b \in B$ the matrix of the transformation $T_{b}$ has zero trace and the endomorphism $\Phi=\frac{1}{|B|} \sum_{b \in B} T_{b}$ also has zero trace. On the other hand, the trace of the endomorphism $E=\frac{1}{|G|} \sum_{g \in G} T_{g}$ is equal to the trace of the operator $\frac{1}{|G|} T_{e}$ and hence it is equal to 1. Consequently the operator $\Phi-E$ has trace -1 and cannot be nilpotent. This contradiction shows that $r(G)>\sqrt{|G|}$.

In the following Table 3 we present the results of computer calculations of basis sizes and characteristics of all non-cyclic Abelian groups $G$ of order $|G| \leq 60$. In this table

$$
l b[G]:=\max \left\{\lceil\sqrt{2|G|+0.25}-0.5\rceil,\left\lceil\sqrt{2|G|-|G| /\left|G_{2}\right|} \mid\right\}\right.
$$

is the lower bound given in Theorems 2 and 8 .

The results of computer calculations given in Table 2, Table 3 and Theorem 1 imply the following lower and upper bounds for the basis characteristic of the class Abelian of finite Abelian groups.

Proposition 3. The class Abelian of finite Abelian groups has basis characteristic

$$
1.7677 \cdots=\frac{5}{\sqrt{8}}=\delta\left[\left(C_{2}\right)^{3}\right] \leq \delta[\text { Abelian }] \leq \frac{4}{\sqrt{3}} \approx 2.3094
$$

Proof. The upper bound $\delta[$ Abelian $] \leq \frac{4}{\sqrt{3}}$ follows from Theorem 1 and the lower bound

$$
\delta[\text { Abelian }] \geq \delta\left[\left(C_{2}\right)^{3}\right]=\frac{5}{\sqrt{8}}
$$

follows from the known value $r\left[\left(C_{2}\right)^{3}\right]=5$.

Question 3. Is $\delta[$ Abelian $]=\delta\left[\left(C_{2}\right)^{3}\right]=1.7677 \ldots$ ? 


\begin{tabular}{|c|c|c|c|c|c|c|c|}
\hline$G$ & $\left(C_{2}\right)^{2}$ & $\left(C_{2}\right)^{3}$ & $C_{2} \times C_{4}$ & $\left(C_{3}\right)^{2}$ & $\left(C_{2}\right)^{2} \times C_{3}$ & $C_{2} \times C_{8}$ & $\left(C_{4}\right)^{2}$ \\
\hline$l b[G]$ & 3 & 4 & 4 & 4 & 5 & 6 & 6 \\
\hline$r[G]$ & 3 & 5 & 5 & 4 & 5 & 7 & 6 \\
\hline$\delta\left[C_{n}\right]$ & 1.5 & $1.7677 \ldots$ & $1.7677 \ldots$ & $1.3333 \ldots$ & $1.4433 \ldots$ & 1.75 & 1.5 \\
\hline \hline$G$ & $\left(C_{2}\right)^{2} \times C_{4}$ & $\left(C_{2}\right)^{4}$ & $C_{2} \times\left(C_{3}\right)^{2}$ & $\left(C_{2}\right)^{2} \times C_{5}$ & $C_{2} \times C_{3} \times C_{4}$ & $\left(C_{2}\right)^{3} \times C_{3}$ & $\left(C_{5}\right)^{2}$ \\
\hline$l b[G]$ & 6 & 6 & 6 & 6 & 7 & 7 & 7 \\
\hline$r[G]$ & 6 & 6 & 7 & 7 & 8 & 8 & 8 \\
\hline$\delta\left[C_{n}\right]$ & 1.5 & 1.5 & $1.6499 \ldots$ & $1.5652 \ldots$ & $1.6329 \ldots$ & $1.6329 \ldots$ & 1.6 \\
\hline \hline$G$ & $C_{3} \times C_{9}$ & $\left(C_{3}\right)^{3}$ & $\left(C_{2}\right)^{2} \times C_{7}$ & $C_{2} \times C_{16}$ & $C_{4} \times C_{8}$ & $\left(C_{2}\right)^{2} \times C_{8}$ & $C_{2} \times\left(C_{4}\right)^{2}$ \\
\hline$l b[G]$ & 7 & 7 & 7 & 8 & 8 & 8 & 8 \\
\hline$r[G]$ & 8 & 8 & 9 & 9 & 10 & 10 & 10 \\
\hline$\delta\left[C_{n}\right]$ & $1.5396 \ldots$ & $1.5396 \ldots$ & $1.7008 \ldots$ & $1.5909 \ldots$ & $1.7677 \ldots$ & $1.7677 \ldots$ & $1.7677 \ldots$ \\
\hline \hline$G$ & $\left(C_{2}\right)^{3} \times C_{4}$ & $\left(C_{2}\right)^{5}$ & $\left(C_{6}\right)^{2}$ & $\left(C_{2}\right)^{2} \times C_{9}$ & $\left(C_{3}\right)^{2} \times C_{4}$ & $\left(C_{2}\right)^{3} \times C_{5}$ & $C_{2} \times C_{4} \times C_{5}$ \\
\hline$l b[G]$ & 8 & 8 & 8 & 8 & 8 & 9 & 9 \\
\hline$r[G]$ & 10 & 10 & 10 & 10 & 9 & 10 & 10 \\
\hline$\delta\left[C_{n}\right]$ & $1.7677 \ldots$ & $1.7677 \ldots$ & $1.6666 \ldots$ & $1.6666 \ldots$ & 1.5 & $1.5811 \ldots$ & $1.5811 \ldots$ \\
\hline \hline$G$ & $\left(C_{2}\right)^{2} \times C_{11}$ & $\left(C_{3}\right)^{2} \times C_{5}$ & $C_{2} \times C_{3} \times C_{8}$ & $C_{3} \times\left(C_{4}\right)^{2}$ & $\left(C_{2}\right)^{2} \times C_{3} \times C_{4}$ & $\left(C_{2}\right)^{4} \times C_{3}$ & $\left(C_{7}\right)^{2}$ \\
\hline$l b[G]$ & 9 & 9 & 10 & 10 & 10 & 10 & 10 \\
\hline$r[G]$ & 11 & 11 & 11 & 11 & 11 & 12 & 11 \\
\hline$\delta\left[C_{n}\right]$ & $1.6583 \ldots$ & $1.6397 \ldots$ & $1.5877 \ldots$ & $1.5877 \ldots$ & $1.5877 \ldots$ & $1.7320 \ldots$ & $1.5714 \ldots$ \\
\hline \hline$G$ & $C_{2} \times\left(C_{5}\right)^{2}$ & $\left(C_{2}\right)^{2} \times C_{13}$ & $C_{6} \times C_{9}$ & $C_{2} \times\left(C_{3}\right)^{3}$ & $C_{2} \times C_{4} \times C_{7}$ & $\left(C_{2}\right)^{3} \times C_{7}$ & $\left(C_{2}\right)^{2} \times C_{3} \times C_{5}$ \\
\hline$l b[G]$ & 10 & 10 & 10 & 10 & 11 & 11 & 11 \\
\hline$r[G]$ & 12 & 12 & 12 & 12 & 12 & 12 & 13 \\
\hline$\delta\left[C_{n}\right]$ & $1.6970 \ldots$ & $1.6641 \ldots$ & $1.6329 \ldots$ & $1.6329 \ldots$ & $1.6035 \ldots$ & $1.6035 \ldots$ & $1.6782 \ldots$ \\
\hline
\end{tabular}

Table 3: Basis sizes and characteristics of non-cyclic Abelian groups $G$ of order $|G| \leq 60$.

In the following Table 4 we present the results of computer calculations of basis sizes and characteristics of all groups $G$ of order $|G| \leq 40$. For calculating we use the system for computational discrete algebra GAP. The command $\operatorname{SmallGroup}(n, k)$ returns the $k$-th group of order $n$ in the GAP catalogue. In Table $4,(n, k)$ denotes $\operatorname{SmallGroup}(n, k)$. In GAP the command StructureDescription $(G)$ gives the description of the structure of a group $G$. For example, StructureDescription(SmallGroup $(16,12)$ ) gives $C_{2} \times Q_{8}$. With the red color we denote Abelian groups, blue are nilpotent non-Abelian groups. All other groups in Table 4 are solvable and non-nilpotent. They are denoted with black color.

The results of computer calculations given in Table 4 and Theorem 1 imply the following lower and upper bounds for the basis characteristic of the class NonAbelian of finite non-Abelian groups.

Proposition 4. The class NonAbelian of finite non-Abelian groups has basis characteristic

$$
1.5=\frac{6}{\sqrt{16}}=\delta\left[C_{2} \times Q_{8}\right] \leq \delta[\text { NonAbelian }] \leq \frac{4}{\sqrt{3}} \approx 2.3094 .
$$

Proof. The upper bound $\delta$ [NonAbelian] $\leq \frac{4}{\sqrt{3}}$ follows from Theorem 1 and the lower bound $\delta[$ NonAbelian $] \geq \delta\left[C_{2} \times Q_{8}\right]=\delta[\operatorname{SmallGroup}(16,12)]=1.5$ follows from the known value $r\left[C_{2} \times Q_{8}\right]=r[\operatorname{SmallGroup}(16,12)]=6$. 


\begin{tabular}{|c|c|c|c|c|c|c|c|c|c|c|c|}
\hline G & $r[G]$ & $\delta[G]$ & G & $r[G]$ & $\delta[G]$ & G & $r[G]$ & $\delta[G]$ & G & $r[G]$ & $\delta[G]$ \\
\hline$(1,1)$ & 1 & 1 & $\begin{array}{l}(18,5) \\
(18)\end{array}$ & 7 & $1.6499 \ldots$ & $(32,2)$ & 8 & $1.4142 \ldots$ & $(32,49)$ & 7 & $1.2374 \ldots$ \\
\hline$(2,1)$ & 2 & $1.4142 .$. & $(19,1)$ & 6 & $1.3764 \ldots$ & $(32,3)$ & 10 & $1.7677 \ldots$ & $(32,50)$ & 7 & $1.2374 \ldots$ \\
\hline$(3,1)$ & 2 & $1.1547 \ldots$ & $(20,1)$ & 6 & $1.3416 \ldots$ & $(32,4)$ & 7 & $1.2374 \ldots$ & $(32,51)$ & 10 & $1.7677 \ldots$ \\
\hline$(4,1)$ & 3 & 1.5 & $(20,2)$ & 7 & $1.5652 \ldots$ & $(32,5)$ & 7 & $1.2374 \ldots$ & $(33,1)$ & 9 & $1.5666 \ldots$ \\
\hline$(4,2)$ & 3 & 1.5 & $(20,3)$ & 5 & $1.1180 \ldots$ & $(32,6)$ & 6 & $1.0606 \ldots$ & $(34,1)$ & 7 & $1.2004 \ldots$ \\
\hline$(5,1)$ & 3 & $1.3416 \ldots$ & $(20,4)$ & 5 & $1.1180 \ldots$ & $(32,7)$ & 7 & $1.2374 \ldots$ & $(34,2)$ & 9 & $1.5434 \ldots$ \\
\hline$(6,1)$ & 3 & $1.2247 \ldots$ & $(20,5)$ & 7 & $1.5652 \ldots$ & $(32,8)$ & 7 & $1.2374 \ldots$ & $(35,1)$ & 9 & $1.5212 \ldots$ \\
\hline$(6,2)$ & 4 & $1.6329 \ldots$ & $(21,1)$ & 6 & $1.3093 \ldots$ & $(32,9)$ & 7 & $1.2374 \ldots$ & $(36,1)$ & 8 & $1.3333 \ldots$ \\
\hline$(7,1)$ & 4 & $1.5118 \ldots$ & $(21,2)$ & 7 & $1.5275 \ldots$ & $(32,10)$ & 7 & $1.2374 \ldots$ & $(36,2)$ & 10 & $1.6666 \ldots$ \\
\hline$(8,1)$ & 4 & $1.4142 \ldots$ & $(22,1)$ & 6 & $1.2792 \ldots$ & $(32,11)$ & 6 & $1.0606 \ldots$ & $(36,3)$ & 8 & $1.3333 \ldots$ \\
\hline$(8,2)$ & 5 & $1.7677 \ldots$ & $(22,2)$ & 8 & $1.7056 \ldots$ & $(32,12)$ & 7 & $1.2374 \ldots$ & $(36,4)$ & 7 & $1.1666 \ldots$ \\
\hline$(8,3)$ & 3 & $1.0606 \ldots$ & $(23,1)$ & 8 & $1.6681 \ldots$ & $(32,13)$ & 7 & $1.2374 \ldots$ & $(36,5)$ & 10 & $1.6666 \ldots$ \\
\hline$(8,4)$ & 4 & $1.4142 \ldots$ & $(24,1)$ & 6 & $1.2247 \ldots$ & $(32,14)$ & 7 & $1.2374 \ldots$ & $(36,6)$ & 8 & $1.3333 \ldots$ \\
\hline$(8,5)$ & 5 & $1.7677 \ldots$ & $(24,2)$ & 8 & $1.6329 \ldots$ & $(32,15)$ & 7 & $1.2374 \ldots$ & $(36,7)$ & 8 & $1.3333 \ldots$ \\
\hline$(9,1)$ & 4 & $1.3333 \ldots$ & $(24,3)$ & 6 & $1.2247 \ldots$ & $(32,16)$ & 9 & $1.5909 \ldots$ & $(36,8)$ & 9 & 1.5 \\
\hline$(9,2)$ & 4 & $1.3333 \ldots$ & $(24,4)$ & 7 & $1.4288 \ldots$ & $(32,17)$ & 7 & $1.2374 \ldots$ & $(36,9)$ & 7 & $1.1666 \ldots$ \\
\hline$(10,1)$ & 4 & $1.2649 \ldots$ & $(24,5)$ & 6 & $1.2247 \ldots$ & $(32,18)$ & 7 & $1.2374 \ldots$ & $(36,10)$ & 7 & $1.1666 \ldots$ \\
\hline$(10,2)$ & 5 & $1.5811 \ldots$ & $(24,6)$ & 6 & $1.2247 \ldots$ & $(32,19)$ & 7 & $1.2374 \ldots$ & $(36,11)$ & 7 & $1.1666 \ldots$ \\
\hline$(11,1)$ & 5 & $1.5075 \ldots$ & $(24,7)$ & 7 & $1.4288 \ldots$ & $(32,20)$ & 7 & $1.2374 \ldots$ & $(36,12)$ & 8 & $1.3333 \ldots$ \\
\hline$(12,1)$ & 5 & $1.4433 \ldots$ & $(24,8)$ & 6 & $1.2247 \ldots$ & $(32,21)$ & 10 & $1.7677 \ldots$ & $(36,13)$ & 8 & $1.3333 \ldots$ \\
\hline$(12,2)$ & 5 & $1.4433 \ldots$ & $(24,9)$ & 8 & $1.6329 \ldots$ & $(32,22)$ & 8 & $1.4142 \ldots$ & $(36,14)$ & 10 & $1.6666 \ldots$ \\
\hline$(12,3)$ & 4 & $1.1547 \ldots$ & $(24,10)$ & 6 & $1.2247 \ldots$ & $(32,23)$ & 8 & $1.4142 \ldots$ & $(37,1)$ & 10 & $1.6439 \ldots$ \\
\hline$(12,4)$ & 4 & $1.1547 \ldots$ & $(24,11)$ & 6 & $1.2247 \ldots$ & $(32,24)$ & 7 & $1.2374 \ldots$ & $(38,1)$ & 8 & $1.2977 \ldots$ \\
\hline$(12,5)$ & 5 & $1.4433 \ldots$ & $(24,12)$ & 5 & $1.0206 \ldots$ & $(32,25)$ & 8 & $1.4142 \ldots$ & $(38,2)$ & 10 & $1.6222 \ldots$ \\
\hline$(13,1)$ & 5 & $1.3867 \ldots$ & $(24,13)$ & 6 & $1.2247 \ldots$ & $(32,26)$ & 8 & $1.4142 \ldots$ & $(39,1)$ & 8 & $1.2810 \ldots$ \\
\hline$(14,1)$ & 5 & $1.3363 \ldots$ & $(24,14)$ & 6 & $1.2247 \ldots$ & $(32,27)$ & 6 & $1.0606 \ldots$ & $(39,2)$ & 10 & $1.6012 \ldots$ \\
\hline$(14,2)$ & 6 & $1.6035 \ldots$ & $(24,15)$ & 8 & $1.6329 \ldots$ & $(32,28)$ & 7 & $1.2374 \ldots$ & $(40,1)$ & 8 & $1.2649 \ldots$ \\
\hline$(15,1)$ & 6 & $1.5491 \ldots$ & $(25,1)$ & 8 & 1.6 & $(32,29)$ & 7 & $1.2374 \ldots$ & $(40,2)$ & 10 & $1.5811 \ldots$ \\
\hline$(16,1)$ & 6 & 1.5 & $(25,2)$ & 8 & 1.6 & $(32,30)$ & 6 & $1.0606 \ldots$ & $(40,3)$ & 8 & $1.2649 \ldots$ \\
\hline$(16,2)$ & 6 & 1.5 & $(26,1)$ & 6 & $1.1766 \ldots$ & $(32,31)$ & 6 & $1.0606 \ldots$ & $(40,4)$ & 8 & $1.2649 \ldots$ \\
\hline$(16,3)$ & 5 & 1.25 & $(26,2)$ & 8 & $1.5689 \ldots$ & $(32,32)$ & 7 & $1.2374 \ldots$ & $(40,5)$ & 8 & $1.2649 \ldots$ \\
\hline$(16,4)$ & 5 & 1.25 & $(27,1)$ & 8 & $1.5396 \ldots$ & $(32,33)$ & 7 & $1.2374 \ldots$ & $(40,6)$ & 8 & $1.2649 \ldots$ \\
\hline$(16,5)$ & 7 & 1.75 & $(27,2)$ & 8 & $1.5396 \ldots$ & $(32,34)$ & 7 & $1.2374 \ldots$ & $(40,7)$ & 9 & $1.4230 \ldots$ \\
\hline$(16,6)$ & 5 & 1.25 & $(27,3)$ & 6 & $1.1547 \ldots$ & $(32,35)$ & 7 & $1.2374 \ldots$ & $(40,8)$ & 8 & $1.2649 \ldots$ \\
\hline$(16,7)$ & 5 & 1.25 & $(27,4)$ & 6 & $1.1547 \ldots$ & $(32,36)$ & 10 & $1.7677 \ldots$ & $(40,9)$ & 10 & $1.5811 \ldots$ \\
\hline$(16,8)$ & 5 & 1.25 & $(27,5)$ & 8 & $1.5396 \ldots$ & $(32,37)$ & 7 & $1.2374 \ldots$ & $(40,10)$ & 8 & $1.2649 \ldots$ \\
\hline$(16,9)$ & 5 & 1.25 & $(28,1)$ & 7 & $1.3228 \ldots$ & $(32,38)$ & 8 & $1.4142 \ldots$ & $(40,11)$ & 8 & $1.2649 \ldots$ \\
\hline$(16,10)$ & 6 & 1.5 & $(28,2)$ & 9 & $1.7008 \ldots$ & $(32,39)$ & 7 & $1.2374 \ldots$ & $(40,12)$ & 8 & $1.2649 \ldots$ \\
\hline$(16,11)$ & 5 & 1.25 & $(28,3)$ & 6 & $1.1338 \ldots$ & $(32,40)$ & 7 & $1.2374 \ldots$ & $(40,13)$ & 8 & $1.2649 \ldots$ \\
\hline$(16,12)$ & 6 & 1.5 & $(28,4)$ & 9 & $1.7008 \ldots$ & $(32,41)$ & 7 & $1.2374 \ldots$ & $(40,14)$ & 10 & $1.5811 \ldots$ \\
\hline$(16,13)$ & 5 & 1.25 & $(29,1)$ & 8 & $1.4855 \ldots$ & $(32,42)$ & 7 & $1.2374 \ldots$ & $(41,1)$ & 10 & $1.5617 \ldots$ \\
\hline$(16,14)$ & 6 & 1.5 & $(30,1)$ & 7 & $1.2780 \ldots$ & $(32,43)$ & 6 & $1.0606 \ldots$ & $(42,1)$ & 7 & $1.0801 \ldots$ \\
\hline$(17,1)$ & 6 & $1.4552 \ldots$ & $(30,2)$ & 7 & $1.2780 \ldots$ & $(32,44)$ & 6 & $1.0606 \ldots$ & $(42,2)$ & 8 & $1.2344 \ldots$ \\
\hline$(18,1)$ & 5 & $1.1785 \ldots$ & $(30,3)$ & 7 & $1.2780 \ldots$ & $(32,45)$ & 10 & $1.7677 \ldots$ & $(42,5)$ & 8 & $1.2344 \ldots$ \\
\hline$(18,2)$ & 7 & $1.6499 \ldots$ & $(30,4)$ & 8 & $1.4605 \ldots$ & $(32,46)$ & 8 & $1.4142 \ldots$ & $(42,6)$ & 10 & $1.5430 \ldots$ \\
\hline$(18,3)$ & 5 & $1.1785 \ldots$ & $(31,1)$ & 9 & $1.6164 \ldots$ & $(32,47)$ & 8 & $1.4142 \ldots$ & $(50,3)$ & 8 & $1.1313 \ldots$ \\
\hline$(18,4)$ & 5 & $1.1785 \ldots$ & $(32,1)$ & 9 & $1.5909 \ldots$ & $(32,48)$ & 8 & $1.4142 \ldots$ & $(50,4)$ & 8 & $1.1313 \ldots$ \\
\hline
\end{tabular}

Table 4: Basis sizes and characteristics of all groups $G$ of order $|G| \leq 40$.

Question 4. Is $\delta[$ NonAbelian $]=\delta\left[C_{2} \times Q_{8}\right]=1.5$ ?

The results of computer calculations given in Table 2, Table 3, Table 4 and Theorem 1 imply 
the following lower and upper bounds for the basis characteristic of the class Groups of all finite groups.

Proposition 5. The class Groups of all finite groups has basis characteristic

$$
1.7677 \cdots=\frac{5}{\sqrt{8}}=\delta\left[\left(C_{2}\right)^{3}\right] \leq \delta[\text { Groups }] \leq \frac{4}{\sqrt{3}} \approx 2.3094
$$

Proof. The upper bound $\delta[$ Groups $] \leq \frac{4}{\sqrt{3}}$ follows from Theorem 1 and the lower bound

$$
\delta[\text { Groups }] \geq \delta\left[\left(C_{2}\right)^{3}\right]=\frac{5}{\sqrt{8}}
$$

follows from the known value $r\left[\left(C_{2}\right)^{3}\right]=5$.

The results of computer calculations suggest the following questions.

Question 5. Is $\delta[$ Groups $]=\delta\left[\left(C_{2}\right)^{3}\right]=1.7677 \ldots$ ?

Question 6. Is $\delta[$ Groups $]=\delta[$ Abelian]?

Problem 1. Is $r\left[S_{n}\right]=\lceil\sqrt{n !}\rceil$ for the symmetric group $S_{n}$ of degree $n$ ?

Remark 1. Computer calculations show that $r\left[S_{n}\right]=\lceil\sqrt{n !}\rceil$ for $n \leq 5$.

Problem 2. Is $r\left[S_{n}\right]=(1+o(1)) \cdot \sqrt{n !}$ as $n \rightarrow \infty$ ? Equivalently, is $\lim _{n \rightarrow \infty} \delta\left[S_{n}\right]=1$ ?

Problem 3. Is $r\left[A_{n}\right]=\lceil\sqrt{n ! / 2}\rceil$ for alternating group $A_{n}$ of degree $n$ ?

Remark 2. Computer calculations show that $r\left[A_{n}\right]=\lceil\sqrt{n ! / 2}\rceil$ for $n \leq 5$.

Problem 4. Is $r\left[A_{n}\right]=(1+o(1)) \cdot \sqrt{\frac{n !}{2}}$ as $n \rightarrow \infty$ ? Equivalently, is $\lim _{n \rightarrow \infty} \delta\left[A_{n}\right]=1$ ?

\section{Acknowledgments}

The authors acknowledge that the proof of Theorem 9 was suggested by the Mathoverflow users lambda, user 49822 and Geoff Robinson, who answered a question posed by the first author at mathoverflow. net/q/384292/61536.

\section{References}

[1] Banakh T., Gavrylkiv V. Algebra in the superextensions of twinic groups. Dissertationes Math. 2010, 473, 1-74. doi:10.4064/dm473-0-1

[2] Banakh T., Gavrylkiv V. Difference bases in cyclic groups. J. Algebra Appl. 2019, 18 (5), article ID 1950081. doi:10.1142/S0219498819500816

[3] Banakh T., Gavrylkiv V. Difference bases in dihedral groups. Int. J. Group Theory 2019, 8 (1), 43-50. doi: 10.22108/ijgt.2017.21612

[4] Banakh T., Gavrylkiv V. Difference bases in finite Abelian groups. Acta Sci. Math. 2019,85 (1-2), 119-137. doi:10.14232/actasm-017-586-x

[5] Banakh T., Gavrylkiv V., Nykyforchyn O. Algebra in superextensions of groups, I: zeros and commutativity. Algebra Discrete Math. 2008, 3, 1-29. 
[6] Bertram E.A., Herzog M. On medium-size subgroups and bases of finite groups. J. Combin. Theory Ser. A 1991, 57 (1), 1-14. doi:10.1016/0097-3165(91)90002-X

[7] Cherly J. On complementary sets of group elements. Arch. Math. 1980, 5, 313-318.

[8] Gavrylkiv V. Bases in dihedral and Boolean groups. J. Integer Seq. 2017, 20 (8), 1-9.

[9] Gavrylkiv V. On the automorphism group of the superextension of a semigroup. Mat. Stud. 2017, 48 (1), 3-13. doi:10.15330/ms.48.1.3-13

[10] Klotz W. Eine obere Schranke für die Reichweite einer Extremalbasis zweiter Ordnung. J. Reine Angew. Math. 1969, 238, 161-168. doi:10.1515/crll.1969.238.161

[11] Kohonen J. An improved lower bound for finite additive 2-bases. J. Number Theory 2017, 174, 518-524. doi: 10.1016/j.jnt.2016.11.011

[12] Moser L. On the representation of 1,2, . , n by sums. Acta Arith. 1960, 6, 11-13. doi:10.4064/ AA-6-1-11-13

[13] Mrose A. Untere Schranken für die Reichweiten von Extremalbasen fester Ordnung. Abh. Math. Semin. Univ. Hambg. 1979, 48, 118-124.

[14] Nathanson M.B. On a problem of Rohrbach for finite groups. J. Number Theory 1992, 41, 69-76.

[15] Robinson D. A course in the theory of groups. Springer-Verlag, New York, 1996.

[16] Rohrbach H. Ein Beitrag zur additiven Zahlentheorie. Math. Z. 1937, 42, 1-30.

[17] Rohrbach H. Anwendung eines Satzes der additiven Zahlentheorie auf eine gruppentheoretische Frage. Math. Z. 1937, 42, 538-542.

[18] Stöhr A. Gelöste und ugelöste Fragen über Basen der natürlichen Zahlenreihe, I. J. Reine Angew. Math. 1955, 194, 40-65.

[19] Kozma G., Lev A. Bases and decomposition numbers of finite groups. Arch. Math. (Basel) 1992, 58 (5), $417-424$. doi:10.1007/BF01190111

Received 22.03.2021

Банах Т.О., Гаврилків В.М. Бази у скінченних групах малого порядку // Карпатські матем. публ. — 2021. — T.13, №1. — С. 149-159.

Підмножина $B$ групи $G$ називається базою групи $G$, якщо кожен елемент $g \in G$ можна подати у вигляді $g=a b$ для деяких елементів $a, b \in B$. Найменша потужність $|B|$ бази $B \subseteq G$ називається базовим розміром групи $G$ та позначається через $r[G]$. Ми доводимо, що кожна скінченна група $G$ має базовий розмір $r[G]>\sqrt{|G|}$. Якщо група $G \in$ абелевою, то має місце нерівність $r[G] \geq \sqrt{2|G|-|G| /\left|G_{2}\right|}$, де $G_{2}=\left\{g \in G: g^{-1}=g\right\}$. Також ми обчислюємо базові розміри всіх абелевих груп порядку $\leq 60$ та всіх неабелевих груп порядку $\leq 40$.

Ключові слова і фрази: скінченна група, абелева група, база, базовий розмір, базова характеристика. 